\title{
Condições ambientais adversas e seus impactos na saúde durante a formação universitária de cantores
}

\section{Adverse surroundings and their health impact during university education of singers}

\author{
(1D) Leila Claudia Monteiro de Castro dos Santos Braga \\ Universidade Federal do Rio de Janeiro, Rio de Janeiro, Brasil \\ leilamonteiro.fono@gmail.com \\ iD Gabriel Eduardo Schütz \\ Universidade Federal do Rio de Janeiro, Rio de Janeiro, Brasil \\ gabriel@iesc.ufrj.br
}

\begin{abstract}
Resumo: Este estudo é oriundo de uma dissertação de mestrado que teve como objetivo investigar a promoção de saúde na formação de cantores em duas universidades públicas do Rio de Janeiro. Durante a pesquisa de campo, as condições ambientais às quais os cantores estavam expostos foram um dos aspectos mais relevantes dentre os observados, tornando-se objeto deste artigo. Os instrumentos utilizados no estudo de campo foram observação participante e entrevistas. A análise das transcrições dos registros orais foi efetuada por meio de uma codificação temática na modalidade da Teoria Fundamentada, e trianguladas com os dados obtidos nas observações. Concluiu-se que as más condições do ambiente de ensino poder-se-iam associar com eventuais agravos à saúde respiratória, vocal, mental e auditiva deste coletivo, podendo ainda influenciar na performance artística do cantor.
\end{abstract}

Palavras chave: promoção da saúde; saúde ocupacional; canto; música.

\begin{abstract}
This study derives from a master's thesis that aimed to examine the promotion of health in singing college students in two public universities in Rio de Janeiro. During the field research, the surroundings to
\end{abstract}


which the singers were exposed to were one of the most relevant aspects amongst the observed, becoming the goal of this article. The instruments used in this field study were participant observation and interviews. The analysis of the transcripts of the oral records was conducted through thematic coding using the method of Grounded Theory and triangulated with the data collected by observation. It was concluded that a bad education environment could be associated with possible damages to the respiratory, vocal, mental and hearing health of this group, and it may still influence the singer's artistic performance.

Keywords: health promotion; occupational health; singing; music.

Submetido em 31 de maio de 2019

Aprovado em 29 de outubro de 2020 
Condições ambientais adversas e seus impactos na saúde durante a formação universitária... Leila Claudia Monteiro de Castro dos Santos Braga • Gabriel Eduardo Schütz

\section{Introdução}

No ano de 1700, o médico Bernardino Ramazzini propôs-se a correlacionar a saúde dos trabalhadores com o ofício que exerciam em seu cotidiano. Em sua obra, intitulada As doenças dos trabalhadores, o autor dedicou um capítulo aos "mestres de dicção, cantores e outros do gênero", demonstrando a existência de agravos ocupacionais, à luz da medicina de sua época (RAMAZZINI, 2016, p. 300). A partir da década de 1980, estudos voltados à saúde dos artistas performáticos passam a se desenvolver de forma mais substancial (FONSECA, 2007, p. 10).

Diferente dos demais músicos, o cantor possui a particularidade de ser ao mesmo tempo o instrumento e o instrumentista. Essa característica faz com que fatores ambientais, emocionais e relacionados à saúde física do cantor interfiram diretamente sobre seu instrumento de trabalho, sendo este indissociável do próprio indivíduo (QUINTA, 2014, p. 21).

A promoção da saúde é o processo de capacitação da comunidade para atuar na melhoria da qualidade de vida e da saúde, buscando um estado de completo bem-estar físico, mental e social. A saúde deve ser vista como um recurso da vida, e fatores políticos, ambientais, econômicos, sociais, comportamentais e biológicos podem vir a beneficiá-la ou prejudicá-la. A participação dos diversos setores da sociedade é um fator essencial para que as ações de promoção da saúde sejam eficazes. As estratégias e programas de promoção da saúde devem adaptar-se às necessidades e possibilidades locais, sendo respeitados os contextos sociais, culturais e econômicos (MINISTÉRIO DE SAÚDE, 2002, p. 9-12).

Acredita-se que as escolas de música têm o poder de influenciar no comportamento dos estudantes ao longo do processo de formação, sendo este um local propício a ações educativas voltadas para a promoção da saúde, devendo estar atentos à saúde musculoesquelética, mental, vocal e auditiva deste coletivo (CHESKY; 
Condições ambientais adversas e seus impactos na saúde durante a formação universitária... Leila Claudia Monteiro de Castro dos Santos Braga • Gabriel Eduardo Schütz

DAWSON; ANCHESTER, 2006, p. 142-143). Os estudantes de música possuem necessidades e preocupações com relação à saúde que diferem dos estudantes de áreas não-musicais, recorrendo à orientação de seus tutores quando necessitam de instrução em questões relacionadas à própria saúde. Essa atitude demonstraria a influência que professores podem ter sobre o comportamento e os hábitos de saúde de estudantes de música. Desta maneira, o investimento em estilos de vida mais saudáveis e em estratégias de prevenção que levassem em consideração a particularidade de cada indivíduo deveriam ser promovidos aos estudantes através das escolas de música (KREURZ; GINSBORG; WILLIAMON, 2009, p. 2-11).

Em uma perspectiva ecológica, o ambiente físico poderia influenciar no bem-estar individual e coletivo, favorecendo ou dificultando a implementação de hábitos saudáveis, sendo importante que se observem as condições ambientais em pesquisas em saúde, bem como a implementação de estratégias voltadas para a promoção da saúde (STOKOLS, 1992, p. 6-11). Acredita-se que o comportamento dos indivíduos pode ser influenciado por um complexo da fatores, incluindo aspectos individuais, comportamentais e ambientais. Tais aspectos deveriam ser levados em consideração no planejamento de ações de promoção da saúde. Os fatores ambientais seriam aqueles externos ao indivíduo e que podem sofrer modificações, influenciando em seu estado de saúde (GIELEN et al., 2008, p. 408-414).

O presente estudo é oriundo de uma dissertação de mestrado que teve como objetivo investigar as práticas de promoção e proteção da saúde existentes no processo de formação do cantor em duas universidades públicas do Rio de Janeiro. Neste artigo, buscou-se analisar os possíveis impactos à saúde decorrentes do ambiente físico no qual os estudantes de canto estão inseridos, levando em consideração as inadequações mencionadas pelos participantes do estudo e observadas durante a pesquisa. 
Condições ambientais adversas e seus impactos na saúde durante a formação universitária... Leila Claudia Monteiro de Castro dos Santos Braga • Gabriel Eduardo Schütz

\section{Metodologia}

Para a elaboração do presente estudo, optou-se pela utilização de uma metodologia qualitativa, capaz de compreender de forma mais profunda as relações humanas e seus significados (MINAYO, 2001, p. 22). Diferente da metodologia quantitativa, na pesquisa qualitativa o pesquisador é parte dos instrumentos da pesquisa, pois traz sua bagagem técnica, intelectual e de experiência de vida, possibilitando uma aproximação com o objeto pesquisado (OLIVEIRA, 2010, p. 22-23). A investigação utilizou o método de triangulação de dados, obtidos através da aplicação de questionários, roteiro de entrevistas e observações participantes, sendo esses os procedimentos mais utilizados em pesquisas de caráter qualitativo, buscando os significados contidos nas falas dos atores sociais investigados (NETO, 2001, p. 57).

A observação é o método que permite ao pesquisador conhecer as práticas e descobrir como algo efetivamente funciona (FLICK, 2009, p. 203). Na observação participante, o pesquisador está inserido no grupo pesquisado, possibilitando a observação do comportamento dos participantes em seu contexto, gerando, desta forma, evidências adicionais para a triangulação dos dados da pesquisa junto a outros procedimentos. A observação é entendida como um dos métodos dos mais indicados para pesquisa em salas de aula (OLIVEIRA, 2010, p. 23). Por sua vez, a entrevista pode ser compreendida como um instrumento de coconstrução da realidade, das subjetividades e dos significados, onde o entrevistador e o entrevistado participam ativamente, sem limitar-se a um processo meramente descritivo (ROLLEMBERG, 2013, p. 42). A relação intersubjetiva entre o entrevistador e o entrevistado proporciona uma melhor compreensão dos significados, valores e opiniões dos atores sociais envolvidos (GONDIM, 2004, p. 140).

A coleta de dados do presente estudo foi realizada entre os meses de setembro e novembro de 2018. As observações participantes ocorreram em disciplinas ministradas no curso de bacharelado 
Condições ambientais adversas e seus impactos na saúde durante a formação universitária... Leila Claudia Monteiro de Castro dos Santos Braga • Gabriel Eduardo Schütz

em música (habilitação canto), com registro em diário de campo para posterior análise do conteúdo. Ao todo, foram observados 24 discentes e 5 docentes, contabilizando setenta horas de observação em sala de aula, além de oito horas de observação em três espetáculos produzidos e executados por discentes e docentes das instituições pesquisadas. Também foram observados os espaços onde se deram as aulas e as apresentações, bem como a relação dos cantores com o ambiente em questão.

Simultaneamente, foram realizadas entrevistas estruturadas, contendo perguntas fechadas de caráter sociodemográfico - em formato de questionário -, e perguntas abertas - em formato de roteiro -, abordando o tema do estudo de forma mais específica. Metade das entrevistas realizadas foi direcionada aos informantes chaves da pesquisa, categoria esta composta por docentes, membros da coordenação do bacharelado em música (habilitação canto) e cantores que se relacionassem de alguma forma com o curso. A outra metade das entrevistas foi direcionada aos discentes que cursavam o bacharelado no momento da pesquisa.

As entrevistas realizadas foram concedidas após consentimento através da leitura e assinatura do Termo de Consentimento Livre e Esclarecido (TCLE), previamente aprovado pelo Comitê de Ética em Pesquisa do Instituto de Estudos em Saúde Coletiva (IESC/ UFRJ), CAAE 91288318.8.0000.5286.

O recrutamento dos informantes chaves foi realizado através da técnica Snowball (técnica "bola de neve"), que consiste em uma amostragem não probabilística que gera um recrutamento em cadeia, geralmente utilizada em pesquisas sociais. Nesta técnica, os participantes iniciais indicam novos participantes que, sucessivamente, indicarão outros participantes, até que seja alcançado o "ponto de saturação", ou seja, o momento em que novos entrevistados já não acrescentam informações relevantes à pesquisa (VINUTO, 2004, p. 203). Para o recrutamento dos discentes foi utilizado convite via correio eletrônico, quando foi apresentado o estudo, bem como sua relevância. 
Condições ambientais adversas e seus impactos na saúde durante a formação universitária... Leila Claudia Monteiro de Castro dos Santos Braga • Gabriel Eduardo Schütz

As entrevistas deram-se nas próprias instituições, mediante agendamento prévio, evitando o deslocamento dos participantes a outros locais, e reduzindo o impacto em sua rotina. Foram entrevistados 12 cantores, sendo 6 discentes (cursando entre o segundo e o penúltimo período do bacharelado) e 6 informantes chaves. Foi utilizado gravador de voz para posterior transcrição e análise do conteúdo falado. Por motivos de sigilo ético, o nome das instituições, bem como dos participantes da pesquisa, não será divulgado. Os nomes dos participantes, apresentados ao longo dos resultados deste estudo, foram substituídos por personagens famosos do teatro musical. A fim de garantir o sigilo, os cursos pesquisados foram denominados curso A e curso B.

Neste estudo, como método de análise do discurso, optou-se pela utilização da Teoria Fundamentada ou Teoria Fundamentada nos Dados ("Grounded Theory") em sua perspectiva construtivista, elaborada por Kathy Charmaz, que tem como base filosófica o construtivismo e o interacionismo simbólico, e que utiliza o conhecimento prévio da literatura como forma de auxílio no desenvolvimento do potencial argumentativo do pesquisador ao longo da análise dos dados (CHARMAZ, 2009, p. 13-25; SANTOS et al., 2018, p. 3-6). Esta modalidade configura-se como uma das abordagens mais usadas para a codificação nas Ciências Sociais, gerando significados teóricos ou propondo hipóteses em forma indutiva, a partir dos dados, sustentando-se na interpretação dos sentidos sem, necessariamente, endossar as visões de mundo dos sujeitos da pesquisa (GIBBS, 2009, p. 71). Para tanto, o conteúdo transcrito foi correlacionado ao contexto das observações participantes, na intenção de ir além das opiniões coletadas, em busca de uma maior aproximação das conjunturas de produção de sentido "no mundo real", alcançando uma melhor avaliação das ações dos sujeitos em sua prática (GRAY, 2012, p. 320). Posteriormente, as falas transcritas foram codificadas e categorizadas segundo sua capacidade de exprimir a percepção sobre o ambiente físico e as consequências e desdobramentos em relação à saúde. A codificação é o processo analítico que permite identificar passagens do 
Condições ambientais adversas e seus impactos na saúde durante a formação universitária... Leila Claudia Monteiro de Castro dos Santos Braga • Gabriel Eduardo Schütz

texto que exemplifiquem alguma ideia(s) temática(s) específica(s) (GIBBS, 2009, p. 77).

\section{Resultados e discussões}

Durante as observações em campo, os ambientes físicos observados compreenderam corredores, salas de aula, salas de estudo e locais de ensaio e apresentação. Apesar de existirem diferenças nos ambientes físicos observados nos cursos A e B, as condições apontadas pelos cantores participantes da pesquisa como inadequadas à saúde, ainda que em maior ou menor grau, foram semelhantes em ambas as instituições pesquisadas. Para análise das queixas relatadas pelos participantes, as condições ambientais foram divididas em cinco categorias de impactos: respiratório/ vocal, acústico, emocional, logístico e corporal. As mesmas foram correlacionadas a seus respectivos impactos à saúde, sendo possível destacar a existência de salas pequenas e com inadequações acústicas de piso, parede ou porta, gerando reverberação intensa da sonoridade durante as aulas e/ou o vazamento do som para o corredor externo; salas com acúmulo de poeira em seu mobiliário; salas com cheiro de mofo; ausência de janelas em sala de aula, consequentemente levando a pouca ventilação e a necessidade de utilização de ar condicionado; e a presença de insetos devido à ausência de vidros em janelas de algumas das salas de estudo, como observa-se no quadro abaixo: 
Condições ambientais adversas e seus impactos na saúde durante a formação universitária... Leila Claudia Monteiro de Castro dos Santos Braga • Gabriel Eduardo Schütz

\section{Quadro 1 - Condições ambientais encontradas nos cursos A e B, descritas pelos participantes da pesquisa}

\begin{tabular}{|c|c|c|c|}
\hline Tipo de Impacto & Condição ambiental & Curso A & Curso B \\
\hline \multirow{3}{*}{ Respiratório/vocal } & Presença de mofo & Sim & Sim \\
\cline { 2 - 4 } & Presença de poeira & Sim & Sim \\
\cline { 2 - 4 } & Pouca ventilação & Sim & Não \\
\hline $\begin{array}{c}\text { Acústico e } \\
\text { emocional }\end{array}$ & Tratamento acústico inadequado & Sim & Sim \\
\hline \multirow{2}{*}{\begin{tabular}{c} 
Logístico e corporal \\
\cline { 2 - 4 }
\end{tabular}} & Salas pequenas & Sim & Sim \\
\cline { 2 - 4 } & Poucas salas disponíveis & Não & Sim \\
\hline
\end{tabular}

Fonte: elaboração própria

\section{1- Impacto respiratório e vocal}

Em relação à primeira categoria, de impacto respiratório e vocal, as questões relacionadas ao cheiro de mofo, à presença de poeira e à ventilação inadequada, elas afetam, principalmente, os alunos alérgicos, como relatado na fala de duas das cantoras entrevistadas:

Eu acho que a gente peca um pouco na estrutura, por exemplo, hoje quando a gente chegou na sala tava com cheiro (de mofo), eu não sou alérgica, agora tem gente que é alérgico e já começa a espirrar, já começa a tossir, já começa a um monte de coisa, e assim, em algumas salas a gente tem essa dificuldade, principalmente as salas de estudo [...] pra quem tem alergia é horrível. (Roxie Hart, 30 anos, cantora).

A nossa estrutura não é adequada [...] A gente frequentemente tem cheiro de mofo, a gente frequentemente não tem janelas, então por não ter janela precisa-se ligar o ar condicionado, um ventilador, ou alguma coisa assim e fica alternando a temperatura. (Maria Von Trapp, 50 anos, cantora). 
Condições ambientais adversas e seus impactos na saúde durante a formação universitária... Leila Claudia Monteiro de Castro dos Santos Braga • Gabriel Eduardo Schütz

Durante a pesquisa de campo observou-se que o impacto respiratório foi uma das queixas mais frequentemente relatadas em relação ao local dos ensaios. O sr. Mistoffelees comenta com os demais que o local em que haviam ensaiado para a ópera no dia anterior estava muito empoeirado e que isso o levou a desenvolver um quadro alérgico: “Tinha muita poeira no chão. Pedimos para limpar, mas continuou muito sujo. Os dançarinos saíram com o pé cortado de tanta poeira que tinha no chão".

Ao ser questionado com relação a sintomas ou desconfortos relacionados a saúde, Tevye, outro cantor, relatou que, embora não fosse alérgico, já sentiu "sensação de garganta fechando" por conta do acúmulo de poeira e do cheiro de mofo presente em uma das salas de estudo.

A exposição a fatores alergênicos é um dos fatores que pode afetar a saúde vocal e respiratória dos cantores. O profissional da voz encontra-se mais exposto a fatores alergênicos devido ao contato mais frequente com teatros empoeirados e coxias sem ventilação. Embora, em um primeiro momento, não afete a saúde vocal, a alergia de grau leve é entendida como a mais problemática já que atinge diretamente a mucosa das pregas vocais, levando a sensação de congestão nasal ou secura na garganta, o que provoca uma irritação crônica que prejudica a emissão vocal, podendo causar quebra de frequência e ressecamento da mucosa ( $\mathrm{COHN}$ et al., 1997 apud BEHLAU et al., 2010, p. 392). Em uma das entrevistas realizadas, Kira observa que os cantores alérgicos necessitam de um cuidado maior com sua saúde:

Sinto falta dos cantores alérgicos serem mais conscientes, porque eles estão com um déficit mesmo, já começam de uma deficiência, vamos dizer assim, né? Ser alérgico para um cantor já é uma questão muito séria. Altera timbre, né? A capacidade de você puxar ar pra dentro... um cantor alérgico tem que ser muito mais alerta com a saúde dele. (Kira, 54 anos, cantora). 
Condições ambientais adversas e seus impactos na saúde durante a formação universitária... Leila Claudia Monteiro de Castro dos Santos Braga • Gabriel Eduardo Schütz

As alergias respiratórias podem causar inflamação e edema na mucosa que recobre o trato respiratório, podendo comprometer a vibração da mucosa das pregas vocais, levando a um quadro de disfonia. Indivíduos alérgicos possuem mais chances de desenvolver disfonias se comparados aos não alérgicos (PRISTON; MEDEIROS, 2013, p. 48). Alterações na função respiratória, ainda que leves, podem ser imperceptíveis na população geral, mas causam impacto ao profissional da voz, podendo gerar quadros de fadiga vocal, extensão vocal reduzida, compensações hiperfuncionais que levem ao abuso vocal, dentre outros, pois afeta a dinâmica da corrente aérea necessária para a fonação (BEHLAU et al., 2010, p. 350).

\section{2- Impacto acústico e emocional}

A segunda categoria, de impacto acústico, diz respeito às condições do ambiente físico que podem gerar agravos à saúde auditiva e emocional dos cantores. Durante a pesquisa de campo foram encontradas salas sem tratamento acústico, algumas com piso frio, sem janelas e/ou com portas de vidro, gerando reverberação sonora e escape do som para os corredores da instituição, interferindo em outras salas de aula próximas. Algumas dessas situações foram descritas pelos cantores ao longo da pesquisa, como no caso das falas abaixo:

[...] A gente está trabalhando em uma sala sem janela, com ar condicionado, uma sala pequena para o tipo de atividade que é, para o volume de voz gerado, para intensidade vocal gerada, problema inclusive para quem está dentro da sala de aula assistindo a aula. [...] Dou aula nessa sala menos três dias (na semana) e eu tenho dor de cabeça e tenho que tomar remédio porque eu não consigo nem dormir [...]. É muito som, numa sala com muito reverbe. (Fantine, 49 anos, cantora). 
Condições ambientais adversas e seus impactos na saúde durante a formação universitária... Leila Claudia Monteiro de Castro dos Santos Braga • Gabriel Eduardo Schütz

\begin{abstract}
Pra mim o problema mais grave é o problema do isolamento acústico [...] na sala em que eu dava aula você tinha que manter a janela fechada, tanto por causa do sol que batia assim, sem dó nem piedade, na sala o dia inteiro, como pelo barulho (da rua) pra você poder ouvir o cantor. Mas, ao mesmo tempo, de um lado tinha aula de trompete, do outro lado tinha aula de violino. Uma concorrência desleal. (Maria Von Trapp, 50 anos, cantora).
\end{abstract}

A audição é uma função essencial para o acompanhamento da música de forma precisa, permitindo ao cantor seguir os demais cantores com quem se apresenta, perceber frequências sonoras que estão normalmente acima das frequências da fala e realizar feedback auditivo, a fim de monitorar a própria qualidade vocal e ajustar sua performance durante a emissão cantada (HU; SATALOFF, 2015, p. 597). Cantores e professores de canto precisam confiar em sua precisão auditiva em todas as frequências audíveis para obter um bom desempenho em sua performance vocal. Sendo assim, uma perda auditiva em qualquer grau pode ser prejudicial para a carreira destes profissionais (ISAAC et al., 2017, p. 22).

Em relação aos riscos de agravos à saúde mencionados pelos cantores ao longo das entrevistas e observações participantes, o risco auditivo foi o menos citado. Em alguns casos, houve menção a queixas de desconforto auditivo devido a inadequações acústicas das salas como um fator de incômodo, mas, exceto por uma cantora em particular, os demais participantes não mencionaram especificamente qualquer preocupação com relação à perda auditiva. Quando questionados acerca da frequência com que realizam exames auditivos, nenhum dos entrevistados relatou realizar exames auditivos com frequência.

Apesar de não estarem expostos a ruídos fabris, os cantores e músicos em geral expõem-se a níveis elevados de pressão sonora. Em estudo de revisão de literatura acerca da saúde auditiva de músicos, Mendes e Morata $(2007$, p. 63,68$)$ ressaltam que as inadequações acústicas são um fator de risco para este coletivo, 
Condições ambientais adversas e seus impactos na saúde durante a formação universitária... Leila Claudia Monteiro de Castro dos Santos Braga • Gabriel Eduardo Schütz

sendo comuns os ensaios em ambientes pequenos e reverberantes. A Perda Auditiva Induzida pela Música (PAIM), causada pela exposição à música em forte intensidade, nem sempre é conhecida pelos músicos, sendo esse desconhecimento um fator em potencial para o risco auditivo.

Outra cantora faz menção a como a interferência de sons externos pode afetar a concentração e a percepção auditiva dos cantores durante as aulas:

\begin{abstract}
Uma questão também de saúde seria a questão do não isolamento acústico... não sei se você reparou, mas isso pode perturbar a concentração de um estudante. Ele não tem tanta concentração e isso pode afetar porque ele não consegue pensar no som dele, ele tá ouvindo uma flauta ali do lado, uma oficina de pandeiro em frente. [...] Acaba reverberando. Ele não reproduz uma acústica ideal pra voz projetada. Poderia ser de madeira, ter todo um tratamento, né? Além do isolamento da porta e das paredes das salas que a gente não tem, isso poderia ser melhor resolvido e isso favoreceria a emissão deles, a compreensão do que rende e do que não rende. (Kira, 54 anos, cantora).
\end{abstract}

Para o aprimoramento do canto, o cantor aciona comandos neuromotores conscientes, que são condicionados ao longo de seu treinamento vocal. Para tanto, faz-se necessária a participação da memória acústica, da afinação e das percepções provocadas pela voz. A audição tem um importante papel, sendo responsável pelo controle da ressonância, afinação, timbre, intensidade, articulação, dentre outros aspectos da produção vocal (CAMPOS, 2007, p. 45).

Outra questão relacionada à inadequação do tratamento acústico diz respeito ao impacto emocional. Segundo uma das participantes, o discente em sala de aula tem o som de sua voz ouvido pelos corredores, e logo reconhecido pelos demais. Sendo a aula o momento para ensaios e erros, o cantor discente sofre com o impacto emocional de ter seus erros expostos publicamente: 
Condições ambientais adversas e seus impactos na saúde durante a formação universitária... Leila Claudia Monteiro de Castro dos Santos Braga • Gabriel Eduardo Schütz

O espaço tem isso que afeta psicologicamente [...] não há pessoa que não passe e não ouça a aula, e como a voz é muito potente [...] a pessoa tá cantando e parece que ela tá cantando do lado de fora, então as pessoas ouvem a aula toda. [...] Isso é muito difícil pra eles, eles ficam cantando no medo, porque a cada aula eles pensam que estão dando um concerto e não, é uma aula de experimento, né? Eles precisam experimentar por tentativa e erro, isso vai deixando eles tensos e aí a musculatura tensa não cede, essa é a importância de se ter um trabalho acústico na sala, pra dar segurança, estar só ele e o orientador ali dentro. (Fantine, 49 anos, cantora).

Os artistas performáticos têm o desafio de conciliar emocionalmente a si mesmos, as próprias expectativas em relação a sua arte e as críticas externas. A alta competitividade vivida por esse coletivo faz com que os artistas performáticos estejam preocupados com o reconhecimento, não sendo o desenvolvimento musical focado apenas em suas características individuais e de personalidade (SWART, 2016, p. 693-696). Os discentes de música convivem, ao longo da graduação, com situações que podem afetá-los psicologicamente, influenciando sua capacidade de concentração e podendo gerar insegurança e medo. São comuns situações de comparação direta com seus pares, competição em audições, cobranças por não alcançarem metas pré-determinadas, dentre outras (ZANDER; VOLTMER; SPAHN, 2010 apud INGLE, 2013, p. 20).

\section{3- Impacto logístico e corporal}

Outro impacto mencionado pelos participantes diz respeito à disponibilidade de salas para as aulas de canto. Esse aspecto divergiu em relação aos cursos, tendo sido mencionado apenas no curso B. A pouca disponibilidade de salas foi levantada pelos participantes como um fator de interferência na logística do curso, 
Condições ambientais adversas e seus impactos na saúde durante a formação universitária... Leila Claudia Monteiro de Castro dos Santos Braga • Gabriel Eduardo Schütz

sendo dificultosa a reposição de aulas, como se pode observar na fala abaixo:

Acho que a gente tem que tocar na questão do espaço físico... acho que a gente poderia ter mais uma sala, de quando você precisar repor alguma aula... Não tem um espaço físico da sala de canto onde estão todos os nossos materiais ou então que tenha o espaço do chão pra eu poder estender um tapete, trabaIhar com o aluno separadamente só a parte física dele... a gente não tem essa estrutura física. (Kira, 54 anos, cantora).

Além do impacto logístico, a fala da informante chave revela a dificuldade em se trabalhar as questões corporais do cantor no espaço físico disponível. Para os discentes, o trabalho corporal para o canto foi mencionado como um de seus anseios dentro do curso de graduação:

\begin{abstract}
Esse semestre, de tanto a gente insistir, a gente pediu e a coordenação conseguiu um professor de dança, que é da [...] e ele vem dar aula pra gente de expressão corporal, e a gente tá fazendo. Mas a princípio seria esse semestre só, os outros alunos que não puxaram não vão ter essa oportunidade. Então, é uma expressão corporal que é mais pra dança, você caminha, você se joga no chão... é quase um balé moderno, sabe? Mas de uma certa forma faz bem ali pro seu corpo, traz um pouco de equilíbrio, traz um pouco de força e eles trabalham não só a parte da laringe, sabendo que a voz vem daqui, mas a gente canta com o corpo. (Éponine, 36 anos, cantora).
\end{abstract}

Essa percepção variou de acordo com a sala utilizada por cada profissional, como podemos ver no relato de uma das cantoras:

As salas (antigas) eram salas pequenas, com um piano de cauda dentro, então o aluno estava sempre atrás do piano de cauda, que era o espaço que tinha pra ficar, de maneira que eu sempre 
Condições ambientais adversas e seus impactos na saúde durante a formação universitária... Leila Claudia Monteiro de Castro dos Santos Braga • Gabriel Eduardo Schütz

via o aluno da cintura pra cima. Quando chegava a época de provas [...] eu olhava pra aquele aluno no palco e dizia assim 'meu Deus, que postura torta!' mas era porque eu não via isso (durante as aulas). Então, assim existem essas inadequações... por incrível que pareça os ambientes agora são maiores e mais fáceis de controlar. (Maria Von Trapp, 50 anos, cantora).

O trabalho corporal é importante para que o cantor seja capaz de ampliar suas percepções e relações com seu próprio corpo, entendendo que este não é algo compartimentado. Para além do dualismo de corpo versus mente e ainda de corpo versus voz, o corpo não se encontra destacado de suas sensações ou da voz, pelo contrário, é um todo indissociável (ESTEVEZ, 2017, p. 103-104).

Durante a observação das aulas ministradas, foi possível perceber momentos em que a necessidade do aprimoramento da consciência corporal se fez presente. Situações em que o discente não era capaz de perceber, de imediato, determinadas tensões musculares que influenciavam na emissão cantada, não conseguindo relaxar determinada estrutura quando solicitado pelo docente; situações em que o discente demonstrou dificuldades com relação à percepção da própria postura corporal, não sendo capaz de alcançar as correções necessárias quando solicitado; ou ainda, em que se fazia necessária a consciência corporal para a parte cênica, quando o discente deveria interpretar determinada emoção cantada ou ainda a intenção do personagem, de acordo com o momento vivido pelo mesmo na música estudada.

O trabalho corporal auxilia o cantor com relação à percepção do próprio corpo, das tensões existentes, de sua própria postura, e o desenvolvimento desta consciência corporal é de grande importância durante seu aprendizado (SCHUSTERMAN, 2012, p. 253257). Uma das cantoras entrevistadas ressalta a importância do trabalho corporal para o cantor, principalmente no que diz respeito à parte cênica, neste caso, a ópera: 
Condições ambientais adversas e seus impactos na saúde durante a formação universitária... Leila Claudia Monteiro de Castro dos Santos Braga • Gabriel Eduardo Schütz

Mas eu sinto que a saúde também passa por essa compreensão do instrumento, a gente reforça essa ideia da voz como um sistema, né? A voz vindo dessa organização do corpo. Quando eles fazem cena na ópera e precisam do corpo, eles já devem estar já preparados com essa consciência, com essa organização do corpo mais resolvida. (Kira, 54 anos, cantora).

\section{Considerações finais}

O estudo realizado nos apresenta as dificuldades relacionadas ao ambiente físico, vividas cotidianamente por docentes e discentes de graduação em música (habilitação canto), e os possíveis impactos gerados na saúde deste coletivo. Durante as observações participantes realizadas na pesquisa de campo, pode-se observar a influência do espaço físico no processo de aprendizagem do canto e na saúde deste coletivo. Também foi possível perceber, ao longo da pesquisa de campo, o empenho dos docentes que, dentro de suas possibilidades estruturais, tentam minimizar as inadequações do ambiente de ensino, seja doando parte do mobiliário, insistindo com relação às questões de limpeza ou se mostrando compreensivos com os desafios emocionais enfrentados pelos discentes.

Os impactos analisados neste estudo podem ser compreendidos em duas categorias: a de consequência direta à saúde do cantor, como o risco de desenvolver quadros alérgicos, disfonias ou perdas auditivas; e a de consequência indireta, caracterizada pelas questões emocionais, mais relacionadas aos riscos voltados para a saúde mental. Para além dos riscos à saúde, ainda foram encontrados impactos logísticos e corporais que poderiam afetar o processo de formação destes profissionais e influenciar em sua performance artística, o que demonstra que as consequências da inadequação do espaço físico são uma questão mais complexa do que possa parecer a um primeiro olhar. 
Condições ambientais adversas e seus impactos na saúde durante a formação universitária... Leila Claudia Monteiro de Castro dos Santos Braga • Gabriel Eduardo Schütz

Espera-se que este estudo venha a contribuir para compreensão das demandas de saúde dos cantores em seu processo de formação e estimule mais investigações nesta área. Tal compreensão é um fator importante para a adequação e manutenção de ambientes mais saudáveis para este coletivo, tanto em relação aos discentes como também para os docentes, minimizando assim o risco de agravos à saúde ocupacional destes profissionais.

\title{
Referências
}

\begin{abstract}
BEHLAU, M. et al. Voz profissional: Aspectos gerais e atuação
\end{abstract} fonoaudiológica. In: BEHLAU, M. Voz. O livro do especialista. Rio de Janeiro: Revinter, v. 2, 2010. Cap. 12, p. 287-407.

CAMPOS, P. H. O impacto da Técnica Alexander na prática do canto: um estudo qualitativo sobre as percepções de cantores com experiência nessa interação. 2007. Dissertação (Mestrado em Música) - Escola de Música, Universidade Federal de Minas Gerais, Belo Horizonte, 2007.

CHARMAZ, K. Construção da Teoria Fundamentada - Guia prático para análise qualitativa. Porto Alegre: Artmed, 2009.

CHESKY, K. S.; DAWSON, W. J.; MANCHESTER, R. Health promotion in schools of music: initial recommendations for schools of music. Medical Problems of Performing Artists, Narberth, v. 21, p. 142-144, set., 2006.

ESTEVEZ, A. M. O atleta da voz: o cantor lírico e seu corpo. 2017. Dissertação (Mestrado em Ciências) - Escola de Artes, Ciências e Humanidades, Universidade de São Paulo, São Paulo, 2017.

FLICK, U. Introdução à pesquisa qualitativa. 3. ed. São Paulo: Artmed, 2009.

FONSECA, J. G. M. Frequencia dos problemas neuromusculares ocupacionais e sua relação com a técnicas pianística - uma leitura transdisciplinar da medicina e do músico. 2007. Tese (Doutorado em 
Condições ambientais adversas e seus impactos na saúde durante a formação universitária... Leila Claudia Monteiro de Castro dos Santos Braga • Gabriel Eduardo Schütz

Clínica Médica) - Faculdade de Medicina, Universidade Federal de Minas Gerais, Belo Horizonte, 2007.

GIBBS, G. Análise de dados qualitativos. Porto Alegre: Artmed, 2009.

GIELEN, A. C. et al. Using the precede-proceed model to apply health behavior theories. In: GLANZ, K.; RIMER, B. K.; VISWANATH, K. Health behavior and health education: theory, research, and practice. $4 \mathrm{a}$. ed. San Francisco: Jossey-Bass, 2008. p. 405-429.

GONDIM, Sônia Maria Guedes. Da fala do outro ao texto negociado: discussões sobre a entrevista na pesquisa qualitativa. Paidéia, Ribeirão Preto, v. 14, n. 28, p. 139-152, Aug. 2004.

GRAY, D. E. Pesquisa no Mundo Real. 2a. ed. Porto Alegre: Artmed, 2012.

HU, A.; SATALOFF, R. T. An update on hearing loss in singers. Journal of Singing, Jacksonville, v. 71, n. 5, p. 597-600, May-June 2015.

INGLE, M. W. K. Evaluation of a trial of an e-health promotion course aimed at Australian tertiary music students. 2013. A thesis for the degree of Master of Music (performance) - Sydney Conservatorium of music, University of Sydney, Sydney, 2013. ISAAC, M. J. et al. Prevalence hearing loss in teachers of singing and voice students. Journal of voice, Filadélfia, v. 31, n. 3, p. 379e.21379e.32, 2017.

KREUTZ, G.; GINSBORG, J.; WILLIAMON, A. Health-promotion behaviours in conservatoire students. Psychology of music, [s. I.], v. 37, n. 1, p. 4760, 2009.

MENDES, H. M.; MORATA, T. C. Exposição profissional à música: uma revisão. Rev. Soc. Bras. de Fonoaudiol, São Paulo, v. 12, n. 1, p. 63-69, 2007.

MINAYO, MARIA CECILIA DE SOUZA. Pesquisa social. Teoria, método e criatividade. Petrópolis: Vozes, 2001.

MINISTÉRIO DA SAÚDE. As cartas da promoção da saúde. MINISTÉRIO DA SAÚDE. Brasília. 2002. 
Condições ambientais adversas e seus impactos na saúde durante a formação universitária... Leila Claudia Monteiro de Castro dos Santos Braga - Gabriel Eduardo Schütz

NETO, O. C. O trabalho de campo como descoberta e criação. In:

MINAYO, M. C. D. S. Pesquisa social. Teoria, método e criatividade.

Petrópolis: Vozes, 2001. p. 51-67.

OLIVEIRA, A. A. D. Observação e entrevista em pesquisa qualitativa.

Revista FACEVV, Vila Velha, p. 22-27, jan.-jun., 2010.

PRISTON, J.; MEDEIROS, T. O que é bom e o que é ruim para a voz? In: PRISTON, J. Dieta vocal. Mitos e verdades sobre a voz. Rio de Janeiro: Autoria, 2013. Cap. 4, p. 37-53.

QUINTA, P. M. R. Ansiedade na performance: educar para prevenir. 2014. Dissertação. (Mestrado em ensino da música - especialidade em canto) - Conservatório Superior de Música de Gaia, Vila Nova de Gaia, p. 1-117. 2014.

RAMAZZINI, B. As doenças dos trabalhadores. 4. ed. São Paulo: Fundacentro, 2016.

ROLLEMBERG, A. T. V. M. Entrevistas de pesquisa: oportunidades de coconstrução de significados. In: BASTOS, L. C.; SANTOS, W. S. D. A entrevista na pesquisa qualitativa. Rio de Janeiro: Quartet : FAPERJ, 2013. Cap. 2, p. 37-46.

SANTOS, J. L. G. et al. Análise de dados: comparação entre as diferentes perspectivas metodológicas da Teoria Fundamentada nos Dados.

Revista da Escola de Enfermagem da USP, São Paulo, v. 25, n.1, p. 1-8, 2018.

SCHUSTERMAN, R. Consciência corporal. Rio de Janeiro: É Realizações, 2012.

STOKOLS, D. Establishing and Maintaining Healthy Environments Toward a Social Ecology of Health Promotion. American Psychologist, Washington, v. 47, n. 1, p. 6-22, 1992.

SWART, I. Ego boundaries and self-steem: Two elusive facets of the psyche of performing musicians. Psychology of Music, [s. I.], v. 44, n. 4, p. 691-709, 2016.

VINUTO, J. A amostragem em bola de neve em pesquisa qualitativa: um debate em aberto. Temáticas, Campinas, v. 22, p. 203-220, ago.-dez. 2014. 